\section{A DIRECT-DEMAND MODEL FOR BICYCLE COUNTS: THE IMPACTS OF LEVEL OF SERVICE AND OTHER FACTORS}

\author{
Daniel J. Fagnant \\ The University of Texas at Austin \\ danfagnant@hotmail.com \\ 512-232-4252 \\ Kara Kockelman \\ (Corresponding Author) \\ University of Texas at Austin \\ Department of Civil, Architectural and Environmental Engineering \\ 301 E. Dean Keeton St \\ Austin, TX 78712 \\ kkockelm@mail.utexas.edu \\ 512-471-0210
}

The following paper is a pre-print, the final publication can be found in Environment and Planning B: Planning and Design 43 (1): 93-107, 2016.

Keywords: Transportation Planning, Bicycle, Cycling, Bike Lanes, Traffic Counts, Level of Service

\title{
ABSTRACT
}

Transportation planning in the US has traditionally focused on automotive traffic but is increasingly turning towards a multi-modal approach in order to accommodate all users. This shift in focus is particularly crucial for cyclists, as 630 were killed and 51 thousand injured on America's roadways in 2009 alone. Unfortunately, most municipalities do not conduct comprehensive bicycle counts to determine where cyclists are riding, though some do seek a scatter of spot-counts. This investigation uses Seattle metropolitan area cyclist count data from 251 locations to develop a direct-demand model for estimating peak-period cyclist counts based on trip generation and attraction factors (such as site-based population and employment densities), as well as cycling-relevant roadway conditions. Roadway condition variables were chosen from the 2010 Highway Capacity Manual's Chapter 17 on urban street segments (including factors like traffic volumes and bike lane width), as well as other physical features like bridge presence and access to bicycle trails. Model results show greatest practical significance for the City of Seattle indicator variable and curb lane width (both of which are correlated with higher counts) and roadway speed (which shows quadratic impacts, with expected counts highest around $35 \mathrm{mph}$ and decreasing as speed becomes higher or lower). The model is implemented in the community of Shoreline, Washington, just north of Seattle, to demonstrate its applicability. As such, the evaluation examines both segment-based bicycle level of service and expected intersection-based counts. Model application findings indicate that 
segment-based bicycle level of service shows little correlation with expected counts, though such information may be used to target new cycling infrastructure improvements.

\section{INTRODUCTION}

States and municipalities are tasked with annually counting the number of motor vehicles traveling their roads through the federally mandated Highway Performance Monitoring System (HPMS). Permanent Automatic Traffic Recorders (ATRs) employing inductive-loop detectors and temporary pneumatic road tubes are typically used to collect vehicle counts at a sample of locations throughout local and state networks (FHWA 2011). This information is then used by transportation planners, designers and policymakers when weighing crucial decisions such as anticipated funding, future needs, and design requirements for proposed projects.

Unfortunately, few states and municipalities have formal procedures for counting bicyclists (Eco Counter 2012). Without a federal mandate, most agencies forego tracking non-motorized forms of travel, other than perhaps conducting a limited assortment of spot-counts at intersections or trail segments. This approach can result in substantial unmet needs and inappropriate investments and policies, as decision-makers rely on minimal demand data for bike routes. To address such shortcomings, this research develops a direct demand model based on bicycle count data in the Seattle, Washington region in combination with other, geo-spatial data in order to estimate peak-hour cyclist counts at urban intersections. While these efforts fall short of a full bicycle count program, they remain a useful way to estimate cyclist counts in locations where direct counts are not available.

\section{BACKGROUND}

The direct-demand model used here is a suitability model, intended to identify the locations where the presence of cyclists is anticipated to be the greatest, based on roadway conditions and a number of other factors. These methods are similar to those used by Davis (1995) to generate suitability models and maps for cyclists. The model developed here differs from many other bicycle suitability models in several key respects. For example, the San Antonio, Texas (SABCMPO 2011), Syracuse, New York (SMTCMPO 2003), and Atlanta, Georgia (Atlanta Bicycle Coalition 2010) models focus on locations that are most conducive to bicycling, such as areas where motorized-vehicle speeds and counts are low, road shoulders are wide, and dedicated lanes often present. While these factors are valuable flow predictors, our model's goal is to determine not where cyclists should be riding, but rather where they are riding. Thus, the model specified here is much more similar to (though less complicated than) KTU\&A's (2011) model and map for the City of Chula Vista, California. KTU\&A's model employed bike-trip attractors (parks, schools, retail, neighborhood civic facilities, etc.) and generators (residential population), along with additional demographic and attraction details, in order to produce a three-stage generation-attraction-routing model. This paper's investigation is also informed by Griswold et al.'s (2011) similar investigation, using two-hour cyclist counts across 81 sites in Berkeley, California, and by McNeil's (2011) exploration of neighborhood "bikeability” in Portland, Oregon, on the basis of infrastructure provision and destination details. 
Cycling suitability models are quite valuable. They can be used by transportation agencies to generate maps for informing cyclists of the most suitable (and safe) routes, as demonstrated by Hochmair and Fu (2009) for Broward County, Florida. They can be used to identify "missing links" in cycling networks, to better plan for new facilities (KTU\&A 2011), and/or improve cycling safety (Allen-Munley et al. 2004). This last need is particularly pressing: the National Highway Transportation Safety Agency (2010) reported that 630 cyclists were killed and 51 thousand injured in 2009 on U.S. roadways. To put this in context, given BTS' (2004) estimate that about $0.2 \%$ of total miles traveled are by bicycle travel, on a per-mile basis cyclists experience fatality rates nearly 30 times higher than passenger car occupants, which is even higher than that of motorcyclists (NHTSA 2010). The cyclist count estimation model investigated here supports such efforts to improve bicycle safety and planning.

\section{DATA ASSEMBLY}

In order to predict bicyclist counts at intersections, suitability attributes for the major roadway approaches at each intersection were developed. These attributes are based on the Highway Capacity Manual's (TRB 2010) Chapter 17 procedures for Bicycle Level of Service (BLOS) at the individual segment-link level, and include a series of 17 equations requiring 6 conditional evaluations (i.e. "if/else" statements). A segment approach is used here, rather than an intersection approach, since the intersection BLOS methodology emphasizes control delay ${ }^{1}$ and requires signal phasing and turning movement information that is often not available. Key (adjustment) factors influencing segment BLOS include cross-section information, motorized vehicle volumes and speeds, and pavement conditions; their required inputs include the number of segment through lanes, outside lane width, outside shoulder width, bike lane width, proportion of occupied on-street parking during the evaluation period, share of heavy vehicles, mid-segment flows, motor vehicle running speeds, and pavement condition information. Other meaningful demand factors were also collected, including population and jobs densities and a residential land use indicator (for predicting trip generation); adjacency to the major cycling trails (e.g. the Interurban Trail and Burke Gilman Trails), and indicator variables for proximity to recreational areas and bridges, as well as other geometric, topographic and roadway features (like the presence of separated bike paths and shared lane use traffic markings, or "sharrows", as shown in Figure 1).

\footnotetext{
${ }^{1}$ Control delay is average time spent waiting at an intersection before proceeding.
} 

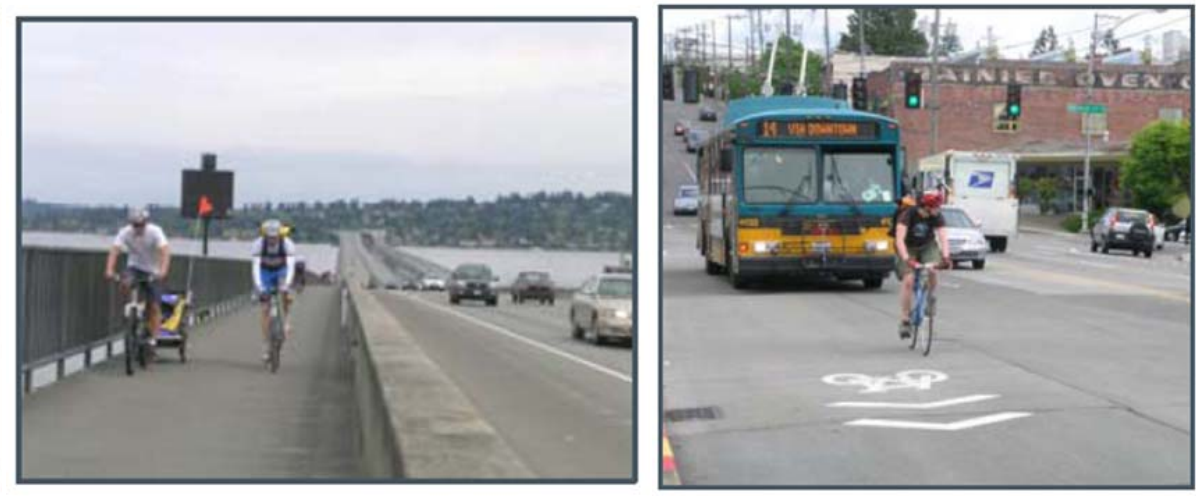

Figure 1: Roadways with Bike Lanes, Separated Bicycle Facilities and Sharrows (Seattle Department of Transportation 2007)

Bicyclist count data was obtained from the Puget Sound Regional Council (PSRC), which conducted extensive counts at intersections (PSRC 2010a) in October 2010, collecting over 340 three-hour counts that month. Data collection was conducted all over the region, though the areas with greater populations were emphasized, with approximately one third of all counts taken within Seattle's city limits. Counts occurred Tuesdays through Thursdays, with each count collected during the hours of 6 AM - 9 AM or 3 PM - 6 PM. Additional information collected at the time of the counts reflected precipitation levels, day of week and mean temperature, but their values did not vary substantially, since all counts were taken during a single month and only one location experienced more than 0.32 inches of precipitation in the 3-hour observation period. All bicycle trail counts were removed, since they do not offer roadway BLOS values and so could not appear in the sample cycling demand regression equations. Similar future efforts could be conducted to develop a suitability model for these trail segments, though this was not conducted in the investigation described here.

Average Annual Daily Traffic (AADT) volumes (for automotive traffic) had to be obtained from numerous sources, covering the cities of Auburn (2009), Bellevue (2010), Bothell (2010), Bremerton (2011), Federal Way (2011), Kent (2009), Kirkland (2008), Lakewood (2010), Lynwood (2005), Puyallup (2008), Redmond (2010), Renton (2010), Seattle (2012), Tacoma (2011), and Kitsap County (2010). While AADT counts spanned several years due to the patchwork jurisdictions, each with their own count program, when multiple count dataset were available for a given location, the dataset closest to October 2010 was chosen. Bike-count locations in Burien, Silverdale, Snohomish, Tukwila and a handful of single-count locations where traffic counts were unavailable had to be excluded from the analysis. In cities with AADT data but missing AADT values for the specific bike-count locations, auto traffic was estimated at 5,000 AADT on the major roadway and 3,000 AADT on the minor roadway within Seattle. Outside Seattle, 3,000 AADT was assumed on the major roadway and 2,000 AADT on the minor roadway. About $12 \%$ of volumes were assigned in this way, with 25 of 32 locations in the City of Seattle.

Year 2010 population data was obtained from the U.S. Census at the census tract level, which was used to compute tract-level population density values. Since many count locations lie on borders between tracts (since important roadways regularly divide census tracts), each site's 
population density estimate was an average from all adjacent tracts. Similarly, employment data (and associated shape files) were obtained from the PSRC for larger Forecast Analysis Zones (FAZs), where are typically on the order of one to 15 square miles in area. As with population density estimates, employment estimates were averaged when count locations fell along the border of two or more FAZs.

Google Earth's satellite photos were used to identify other factors, such as the number of lanes, parking presence, and bicycle lane details at individual locations, as noted above. Curb lane width (for the lane closest to the curb) and bicycle lane-plus-shoulder widths were estimated using Google Earth's measuring tool, taking measurements from the middle of the painted lines/edge striping to the edge of traveled way or gutter-pan (if present). Widths for bike lanes and shoulders with no parking present were combined into a single category (referred to in Table 1 and hereafter as "bike lane width"), since it was often difficult to distinguish the two from satellite photos. While modelers wishing to conduct similar investigations using these methods may use HPMS data to possibly better assess these features, such values were not available here (and they may not be meaningful for cyclists, who do not know what values engineers have logged in the HPMS data set: they only know what they see on the road, as visible in Google Earth images). Speed limits were estimated based on a combination of factors, including roadway functional classification, intersection density, roadway width, on-street parking, and land use, as well as comparisons to similar streets in Shoreline (the city used later for model application) for which speed data was available (City of Shoreline 2012b). A bridge indicator for crossing the region's water bodies was included to account for impacts of limiting possible route choices. Also, a residential land use indicator was used based on adjacent development, with the requirement that all corners must be residential land use for the location to be counted as residential. Each location was counted either during the AM peak or PM peak, though not both. Table 1 summarizes the collected data for all count locations, with subsections separating factors impacting cyclist trip generation and attraction from factors impacting the roadway environment, and temporal factors (precipitation, time of day, and temperature).

29

Table 1: Cyclist Count Location Attribute Summary

\begin{tabular}{|l|c|c|c|c|}
\hline Variable & Mean & Min. & Max. & Std. Dev. \\
\hline Bicycle Count (in 3-hour period) & 36.3 & 0 & 578 & 75.4 \\
\hline Seattle & 0.363 & 0 & 1 & 0.48 \\
Pop. Dens. (1000 / sq. mi.) & 2.29 & 0.123 & 10.0 & 1.83 \\
Empl. Dens. (1000 / sq. mi.) & 8.58 & 0.279 & 70.2 & 13.0 \\
Bike Trail Access & 0.036 & 0 & 1 & 0.19 \\
Bridge & 0.032 & 0 & 1 & 0.18 \\
Recreational Area Access & 0.092 & 0 & 1 & 0.29 \\
\hline AADT (1000s) & 14.6 & 0.538 & 59.3 & 11.5 \\
Median Present & 0.06 & 0 & 3 & 0.29 \\
\# Lanes & 3.49 & 1 & 8 & 1.38 \\
Curb Lane Width (ft.) & 11.22 & 8.20 & 19.65 & 1.61 \\
Bike Lane Width (ft.) & 0.89 & 0 & 6.96 & 1.94 \\
Sharrows & 0.084 & 0 & 1 & 0.28 \\
Separated Path & 0.020 & 0 & 1 & 0.14
\end{tabular}




\begin{tabular}{|l|c|c|c|c|} 
Speed (mph) & 32.5 & 25 & 50 & 4.57 \\
Parking Present & 0.215 & 0 & 1 & 0.41 \\
Residential & 0.175 & 0 & 1 & 0.38 \\
\hline Precipitation (in.) & 0.07 & 0 & 8.06 & 0.51 \\
AM Period & 0.530 & 0 & 1 & 0.50 \\
Mean Temp. (deg. F) & 52.89 & 44 & 58 & 3.18 \\
\hline
\end{tabular}

This summary data show that $36 \%$ of all counts were collected within the City of Seattle, and employment density was higher than population density in $76 \%$ of all count locations. Motorized-vehicle traffic volumes were typically moderate (averaging 14,620 AADT), as were traffic speeds (averaging $32 \mathrm{mph}$ ). About $18 \%$ of all count locations featured bike lanes, which averaged 4.9 feet in width when present. A scattering of count locations were on bridges (3.2\%), near bike trails (3.6\%), near recreational areas like parks or arenas $(9.2 \%)$, or in residential areas (17.5\%); but most count locations were in commercial areas, with none of these features.

While the data collection for this analysis was extensive, it can be improved. For example, heavy vehicle shares and pavement conditions appear in BLOS equations, as noted above, but were not included here due to data availability issues and difficulties in assessing pavement conditions using satellite images. This is made even more difficult since two or more years often separated the Google Earth images from cyclist counts. Only motor vehicle AADTs and major-street geometric features were assembled, due to frequently missing traffic volumes.

\section{DIRECT-DEMAND MODEL}

Using the cyclist count data and location-specific explanatory variables noted above, three cyclist count estimation models were developed. These models included a preliminary Poisson regression count model (P1), a secondary Poisson regression count model (P2) that permits heteroskedasticity in error terms by using robust error terms, and a negative binomial model (NB). The negative binomial model (NB) takes the following form, as noted in Greene (2011):

$$
\begin{aligned}
& Y \sim \text { Poisson }(\lambda+\varepsilon), \text { where } E[Y \mid \boldsymbol{x}, \varepsilon]=\exp \left(\boldsymbol{\beta}^{\prime} \boldsymbol{x}+\varepsilon\right)=h \lambda, \\
& h=\exp (\varepsilon) \sim \operatorname{Gamma}(\theta, \theta), \lambda=\exp \left(\alpha+\boldsymbol{\beta}^{\prime} \boldsymbol{x}\right), \text { and } \\
& \operatorname{Prob}\left(y_{i}=j \mid \boldsymbol{x}_{\boldsymbol{i}}\right)=\frac{\exp \left(-h_{i} \lambda_{i}\right)\left(h_{i} \lambda_{i}\right)^{j}}{j !}, \text { for } j=0,1, \ldots .
\end{aligned}
$$

The gamma error term $(\varepsilon)$ has a unit mean and variance $1 / \theta$, where $\theta$ is called the dispersion parameter. The Poisson-gamma interaction results in a negative binomial distribution for cyclist counts, conditioned on an individual's explanatory factors $\boldsymbol{x}$. The vector of parameters $\boldsymbol{\beta}$ was estimated using weighted maximum-likelihood regression, in Stata software.

Transformations and interactions of various covariates were also investigated, as potential explanatory variables (e.g., natural log and squared transformations of the density variables, traffic volumes (AADT), speed, and curb and bike lane widths). Count-specific indicator variables were also tested, along with Seattle- and Tacoma- specific indicator variables. These location-specific indicator variables served two purposes: they served as a proxy for the larger 
1 population (for trip generation) and employment/destinations (for trip attraction) that can most

2 easily access the count location, and they helped identify whether the populations' latent

3 propensity for cycling was stronger in some areas than others.

The model was then first estimated using all potential explanatory variables, then dropping variables using stepwise elimination until all remaining explanatory variables were statistically significant at the 5\% level. As expected, due to its behavioral flexibility, the NB model is preferred, though all results are shown in Table 2, and used in later discussion. For the preferred NB model, elasticity values were also estimated by perturbing coefficient values by $1 \%$ and observing the resulting impact on estimated cyclist counts. For example, if curb lane widths uniformly increase by $1 \%$, a resulting $0.56 \%$ increase in regional counts could be expected.

Table 2: Poisson Regression Bicycle Count Estimation Model

\begin{tabular}{|c|c|c|c|c|c|c|c|}
\hline \multirow{2}{*}{ Variable } & \multicolumn{2}{|c|}{ Poisson (P1) } & \multicolumn{2}{|c|}{ Poisson w/ RSE (P2) } & \multicolumn{3}{|c|}{ Neg. Bin. (NB) } \\
\hline & Coef. & Std. Dev. & Coef. & Std. Dev. & Coef. & Std. Dev. & Elasticity \\
\hline Constant & -14.55 & 1.04 & -9.412 & 3.363 & $-4.185^{*}$ & 2.019 & -4.10 \\
\hline Seattle & 1.782 & 0.045 & 1.842 & 0.225 & 1.64 & 0.152 & 1.27 \\
\hline Pop. Dens. (1000 / sq. mi.) & 0.070 & 0.011 & - & - & - & - & - \\
\hline Empl. Dens. (1000 / sq. mi.) & 0.012 & 0.003 & - & - & - & - & - \\
\hline Ln (Empl. Dens.) & 0.134 & 0.022 & 0.204 & 0.06 & 0.175 & 0.042 & 0.34 \\
\hline Pop. D. * Empl. D. / 1000 & -2.090 & 0.688 & - & - & - & - & - \\
\hline Bike Trail Access & 1.327 & 0.038 & 1.281 & 0.261 & 1.255 & 0.32 & 0.21 \\
\hline Bridge & 1.302 & 0.054 & 1.477 & 0.209 & 1.117 & 0.256 & 0.25 \\
\hline Recreational Area Access & 0.208 & 0.042 & - & - & - & - & - \\
\hline Curb Lane AADT (1000s) & -0.070 & 0.008 & - & - & - & - & - \\
\hline AADT (1000s) & -0.050 & 0.010 & $-0.012 *$ & 0.006 & - & - & - \\
\hline Ln (AADT) & 0.475 & 0.081 & - & - & - & - & - \\
\hline $\mathrm{AADT}^{2} / 1000$ & 0.556 & 0.101 & - & - & - & - & - \\
\hline Median Present & -0.426 & 0.066 & - & - & - & - & - \\
\hline Curb Lane Width (ft.) & 4.557 & 0.791 & - & - & 0.558 & 0.256 & 0.58 \\
\hline Curb Lane Width $^{2}$ (ft.) & -0.509 & 0.105 & - & - & - & - & - \\
\hline Bike Lane Width (ft.) & 0.240 & 0.072 & - & - & $0.597 *$ & 0.282 & 0.11 \\
\hline Sharrows & -0.447 & 0.044 & - & - & - & - & - \\
\hline Separated Path & 1.209 & 0.043 & 0.916 & 0.245 & 1.163 & 0.352 & 0.24 \\
\hline Speed (mph) & 0.733 & 0.056 & 0.678 & 0.197 & 0.357 & 0.119 & $\begin{array}{l}12.17 \\
(0.42)\end{array}$ \\
\hline Speed $^{2} / 1000$ (mph) & $\begin{array}{c}- \\
10.373\end{array}$ & 0.857 & -9.536 & 2.898 & -5.269 & 2.017 & $\begin{array}{l}-5.35 \\
(0.42)\end{array}$ \\
\hline Residential & -0.482 & 0.046 & -0.544 & 0.169 & -0.397 & 0.135 & -0.03 \\
\hline AM Period & -0.527 & 0.038 & $-0.484^{*}$ & 0.222 & -0.56 & 0.103 & -0.41 \\
\hline Mean Temp. & 0.014 & 0.005 & - & - & - & - & - \\
\hline Over-dispersion Param. $(\theta)$ & - & - & - & - & 0.427 & 0.046 & - \\
\hline
\end{tabular}




\begin{tabular}{|c|c|c|c|}
\hline Pseudo $\mathbf{R}^{2}$ & 0.7585 & 0.7369 & 0.506 \\
\hline Log-Likelihood & -2280.1 & -2484.3 & -971.09 \\
\hline
\end{tabular}

$\mathrm{N}_{\mathrm{obs}}=251, \mathrm{RSE}=$ robust standard errors.

* indicates statistical significance at the $5 \%$ level; all other covariates statistically significant at the $1 \%$ level. Parentheses indicate the joint elasticity effects of both Speed and Speed ${ }^{2}$ covariates

\section{MODEL ANALYSIS AND ASSESSMENT}

The model results suggest many things. First, the natural log of employment density, bike trail access and Seattle indicator variables have positive coefficients. These coefficients are intuitively consistent since all three covariates serve as bicycle trip attractors, with the Seattle indicator variable also representing a trip generator. The Seattle variable by far exhibited the greatest elasticity (and practical significance) outside of the decoupled speed covariates, and employment also showed notable practical significance. Population density (for trip generation) and recreational area proximity (for trip attraction) also appear with positive coefficients in the P1 model, though their absence in the other two models suggests a weaker connection to cyclist counts. As expected, the bridge-variable's coefficient is estimated to be positive, since bridges tend to funnel travelers from many routes into a single crossing route.

It is also interesting to understand the interactions of population and employment in the P1 model, as compared to the other two models, as shown in Figure 2. This figure illustrates how cyclist counts rise with employment density, but eventually taper off (and may actually fall off, if both employment and population density levels are high, presumably as trip distances shorten, streets congest, and travelers can turn to walking). It should be noted the high end of these $\mathrm{x}$-axis values are rarely seen in Seattle: employment density exceeds 30,000 jobs per square mile in just $5 \%$ of the count sizes, and in only one of those observations was population density at least 5,000 persons per square mile.

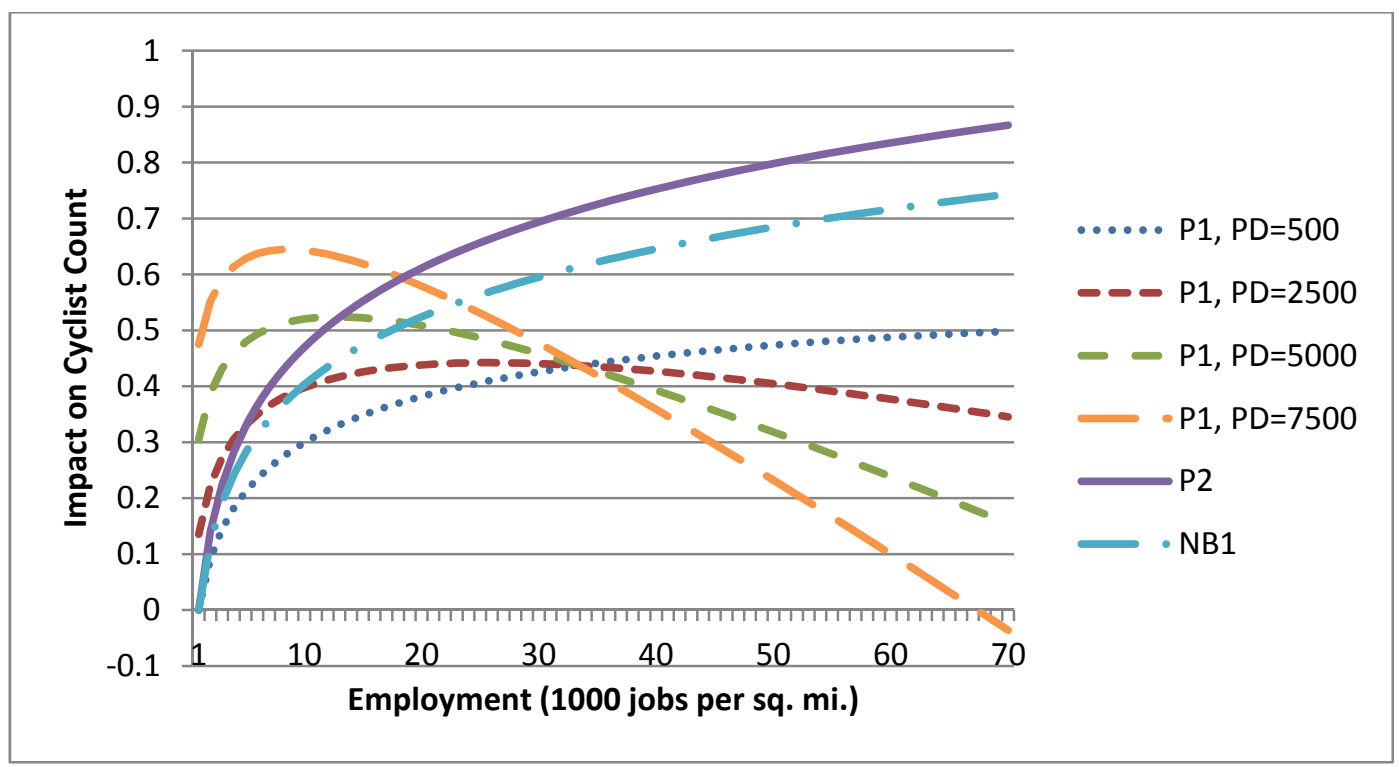

Figure 2: Model-Predicted Impacts of Employment and Population Density on Cyclist Counts Notes: $\mathrm{PD}=$ Population density per sq. mi. Chart normalized for $\mathrm{P} 1$ so intercept $=0$ at $\mathrm{PD}=500 \& \mathrm{ED}=0$. 
1 In addition to trip generation and attraction, the roadway environment was found to significantly

2 impact cyclist counts across locations. It is meaningful to compare the impacts of BLOS-

3 estimated values with those of the count models developed here, as shown in Table 3. Here,

4 model results are compared against the HCM BLOS formula values using roadway

5 characteristics contained in both sets of models. Table cells list whether the key measures

6 positively or negatively impact cyclist counts and HCM BLOS, as well as their functional

7 relationship to the key measures. Lower scores on the HCM BLOS index represent better

8 cycling conditions, so any positive impacts noted in Table 3 should be taken to represent lower

9 HCM BLOS values.

Table 3: Comparison of Cyclist Count Models and HCM BLOS

\begin{tabular}{|l|c|c|c|c|}
\hline \multirow{2}{*}{\multicolumn{1}{|c|}{ Parameter }} & \multicolumn{3}{c|}{ Impact on Cyclists } & \multirow{2}{*}{ Agreement } \\
\cline { 2 - 4 } & Model P2 & Model NB & HCM BLOS & \\
\hline Bike Lane Width & - & Linear, Positive & Square, Positive & Partial \\
Curb Lane Width & - & Linear, Positive & Square, Positive & Partial \\
Curb Lane AADT & - & - & Log, Negative & Partial \\
Segment AADT & Linear, Negative & - & - & Partial \\
Speed & Lin./Sq., Mixed & Lin./Sq., Mixed & Log, Negative & Possible \\
\hline
\end{tabular}

As Tables 2 and 3 indicate, increased bike lane widths and curb lane widths are correlated with higher cyclist counts in the NB model, with bike lane widths exhibiting a slightly stronger impact than curb lane widths. This is consistent with the HCM BLOS formulations, though the estimated impacts are linear, rather than quadratic/squared. In terms of practical effects, curb lane width has a relatively high elasticity value (when compared to bicycle lane width as well as other values), due in part to the presence of curb lanes at all count locations.

While the NB model specification does not suggest that automotive traffic volumes impact cyclist counts in any statistically significant way (given the relatively small data set used here), statistically significant impacts were estimated in the P1 and P2 models. Both models showed generally negative impacts of rising AADT on estimated cyclist counts (in agreement with the HCM BLOS), though some key differences emerge, as shown in Figure 3. 


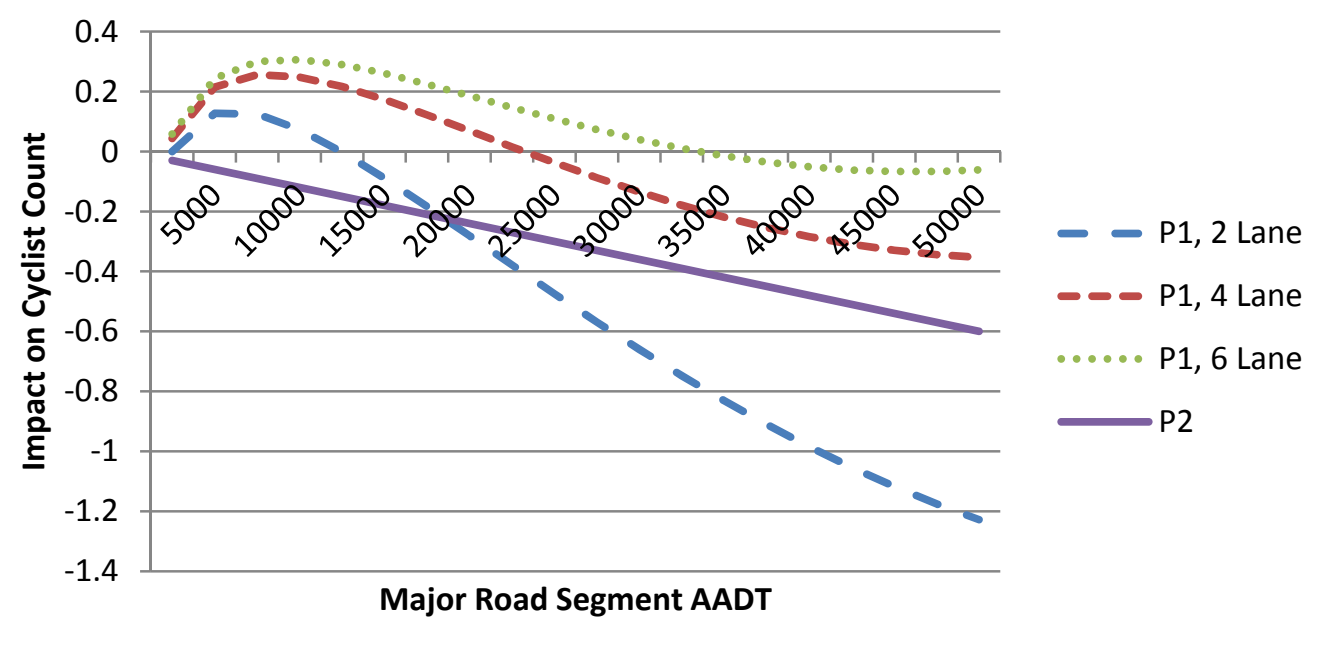

Figure 3: Impacts of Major Road Segment AADT on Cyclist Counts

Note: Chart normalized for P1 so intercept $=0$ at AADT $=2500$ with 2 lanes.

Model P1 exhibits consistency with the HCM BLOS formulas in both the logarithmic functional component and the use of curb lane traffic volumes, rather than just road segment AADTs. However, at low traffic volumes model P1's application will continue to generate higher predicted cyclist counts until curb lane volumes reach about 2500 vehicles per day. While the P2 model suggests linear impacts and relies on segment AADTs rather than curb lane volumes, this model and its overall impacts are preferred to those of P1, thanks to its greater functional flexibility, helping avoid the issues encountered in the P1 model in the presence of low AADT values.

Speed limit impacts in the cyclist count model offer both positive and negative impacts, thanks to the presence of a squared speed limit term with a negative coefficient estimate. The resulting concave response prediction exhibits its greatest positive impacts at roughly $35 \mathrm{mph}$ (slightly below 35 mph in model NB and slightly above in P1 and P2), as illustrated in Figure 4.

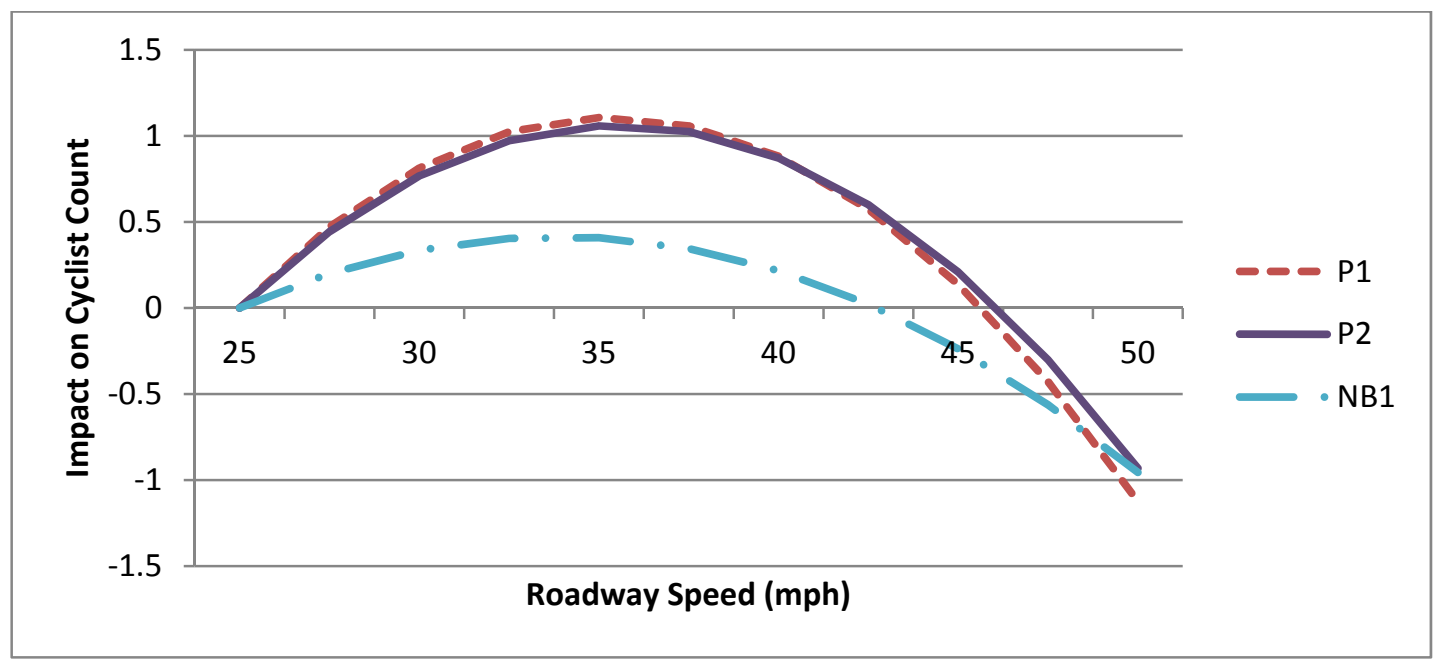

Figure 4: Impacts of Roadway Speed on Cyclist Counts Note: Chart normalized so intercept $=0$ at $25 \mathrm{mph}$ in all models. 
Cyclist utility may be the driving factor here, explaining the discrepancy between the countmodel predictions and those from HCM BLOS formulae. Locations with low speeds are less likely to like along more popular cycling routes, with bike trips concentrating on higher-speed collectors and arterials, much like car traffic concentrates on higher-order roadway facilities. Lower speeds (and speed limits) may also come with high intersection density, creating additional cyclist conflicts with autos and stops. However, the model predictions suggest that cyclists tend to avoid the highest speed roads and seek other routes. (Recall that the data set's speed values are estimates, so trends may vary a bit, if true speed limits and actual traffic speeds are controlled for throughout.) When taken individually, the speed-related covariate elasticities dominate other factors. However, even jointly speed is the third most influential input for predicting cyclist counts, with elasticity values indicating that slight increase in system-wide speeds would lead to a corresponding increase in cyclist counts.

Other estimates' signs are also readily explained. For example, the presence of separated paths comes with significantly higher cyclist counts across all models, which may simply come from designers working to provide separated paths at high-demand/high-use locations; and, once constructed, they are likely to attract even more cyclists. Residential areas are regularly on road systems enjoying less network connectivity (e.g., those having cul de sacs), and offer fewer trip attractors than commercially developed areas, which may explain the negative coefficient across all three models. Cyclists were also predicted to prefer afternoon riding to morning, which is consistent with motorized traffic counts. (More trips are made in the afternoons, right after school and work.)

Three other explanatory variables emerged in the P1 model, but not in the P2 or NB model, so their associated implications should be examined with some caution. In the P1 model, the presence of a median is associated with lower roadway cycling suitability, perhaps due to restrictions on bike maneuverability (as well as higher traffic flows, but this variable was controlled for already). Non-intuitively, sharrows were estimated to have a negative impact on cycling suitability, perhaps because such measures were taken as interim measures (in lieu of providing dedicated bicycle lane)s; or it could simply be a false-positive arising in the model (due to the Poisson specification's less flexible structure). Finally, warmer temperatures appeared generally preferred, within the observed 44 to 58 degrees (Fahrenheit) range.

\section{MODEL APPLICATION}

Both models P2 and NB were applied to the City of Shoreline, Washington, a small municipality of 53,000 persons within a 12.3 square mile area (City of Shoreline 2012a), located just north of Seattle in the northwest corner of King County as shown in Figure 5. 

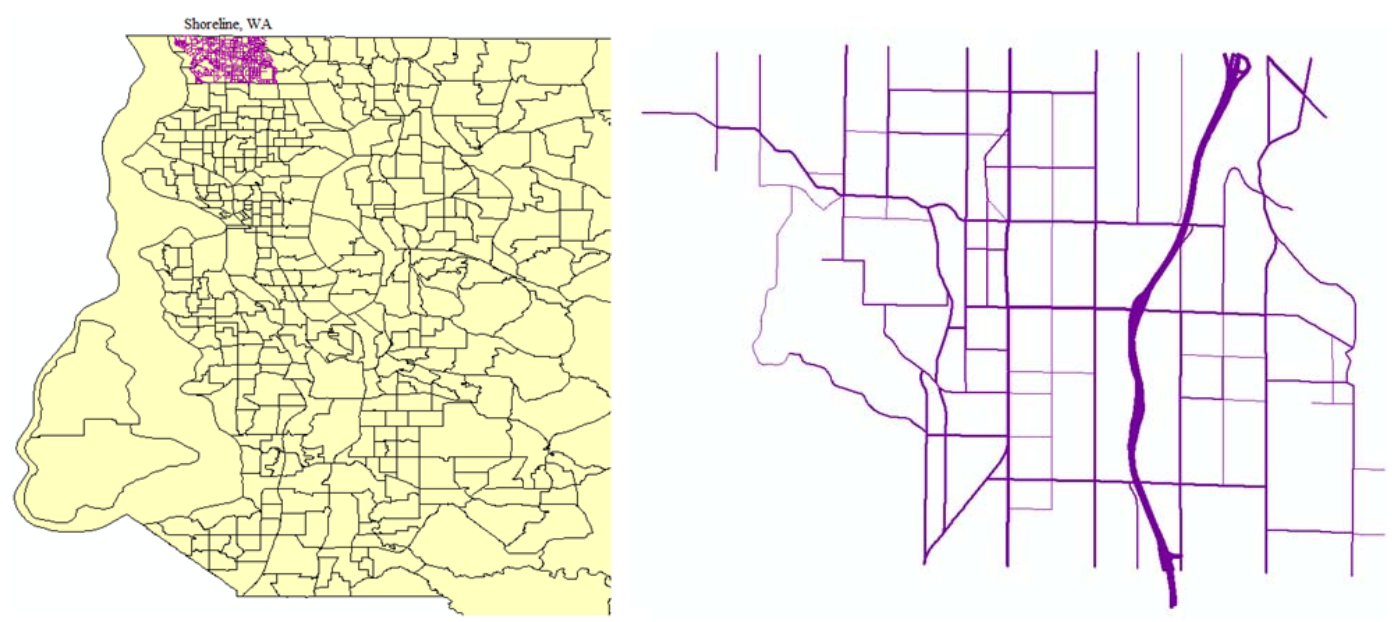

Figure 5: Shoreline, WA Location in the Northwest Corner of King County (Left) and Shoreline Roadway Transportation Network (Right) with Line-weights Representing Auto Traffic Flows

Roadway traffic counts (AADTs) and 24-hour average weekday speeds were obtained from the City of Shoreline (2012b). All roadway links with less than 1,000 AADT were eliminated, to ensure a reasonable number of sample links while eliminating cul-de-sacs and minor residential streets that should expect very low levels of cyclist traffic. This resulted in a final sample of 182 (bi-directional) segment links and 106 intersections. Shoreline is covered by two FAZs and is composed of 13 census tracts, providing some variation and diversity in model inputs/site attributes. Once traffic, speeds, employment, population and roadway characteristics were compiled, the HCM BLOS model was applied to the City of Shoreline's links and cyclist estimation count models were applied to Shoreline's intersections, resulting in Figure 6's two maps (both using model P2) and Figure 7's two maps (using the NB specification). These figures both assume an afternoon count, and estimate intersection cyclist counts based on major (higher AADT) road characteristics. Each individual road link also shows the HCM BLOS score (where high values represent poor level of service), assuming constant values for reasonably good pavement condition (scoring 4 out of 5) and 5\% heavy truck volumes. 


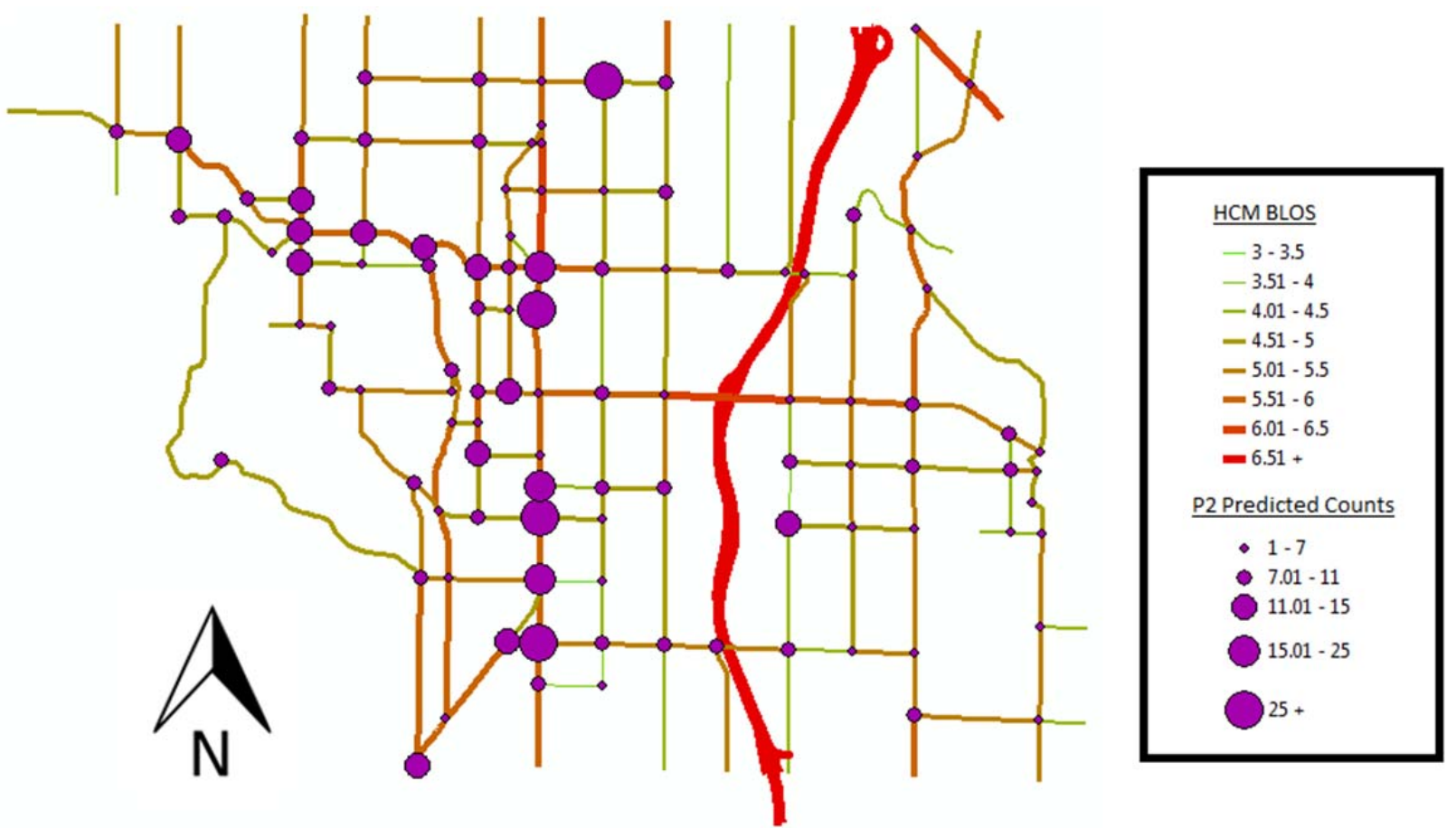

1 2 3

Figure 6: Bicycle Counts for Shoreline, Washington, using HCM BLOS on Links and P2 Model Forecasts for Intersection Counts
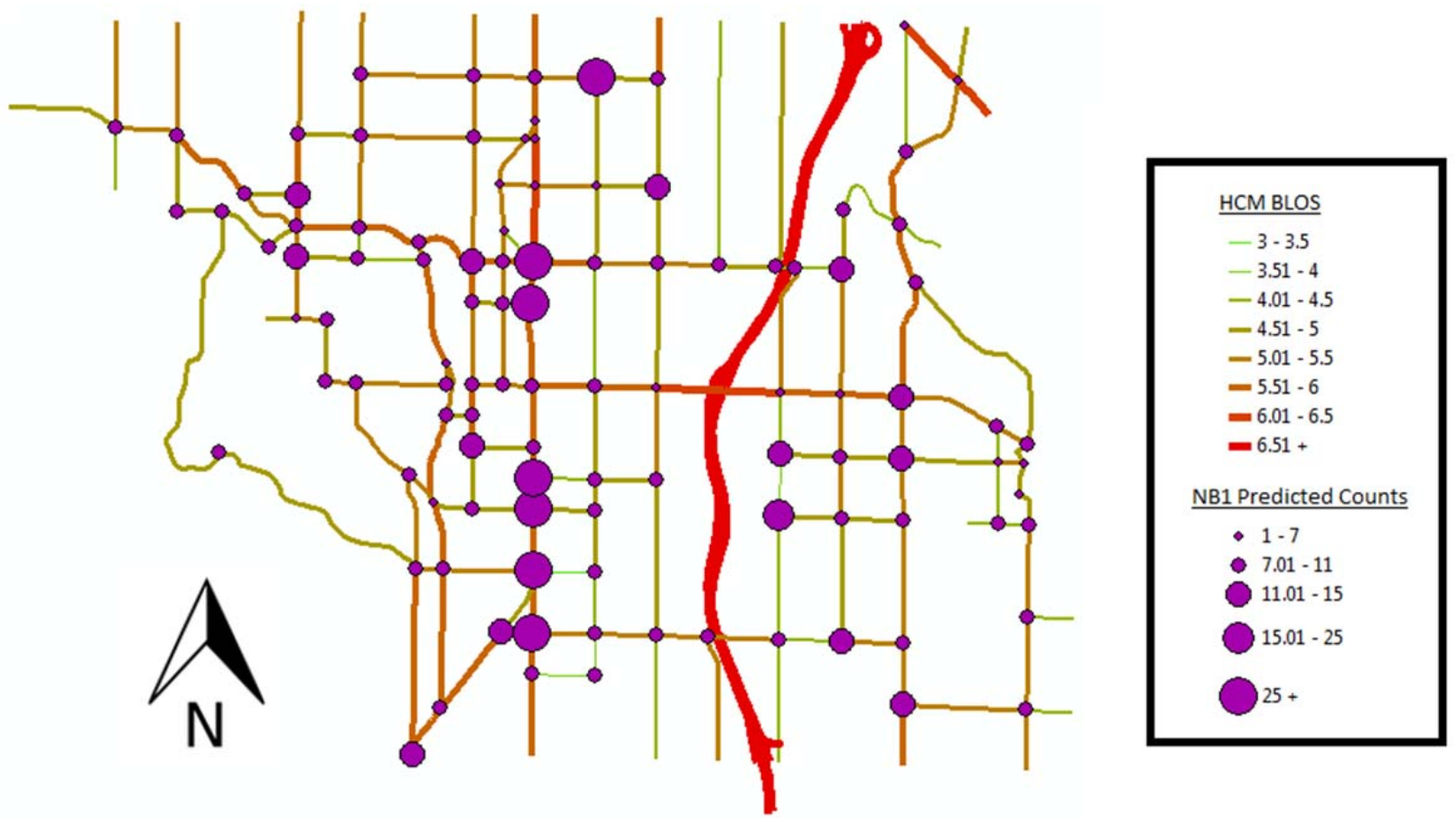

4 5 6 7

Figure 7: Bicycle Counts for Shoreline, Washington, using HCM BLOS on Links and NB Model Forecasts for Intersection Counts

Important inferences may be made when comparing the two maps and count model applications. First, the NB model estimated consistently higher intersection counts (of cyclists) than the P2 model did. NB model predictions ranged from 5.4 to 49.2 cyclists (per 3-hour afternoon period), 
averaging 10.2 with a standard deviation of 6.7, in contrast to the 3.4- to 31.8-cyclists range, 8.6cyclist average, and 5.0-cyclist standard deviation under the P2 model.

Despite these minor differences, however, the two models generated very similar results. Both models showed strong agreement regarding locations with the greatest number of cyclists. These intersections ran north-south along Aurora, cutting slightly east at the far northern end. These locations aligned with access to the Interurban (bicycle) Trail, though it should be noted that the trail skews slightly east of a few intersections, which the map clearly shows as having lowered count estimates. When excluding these seven intersections, the two models remain in relative agreement when identifying higher-usage locations. For example, model NB identifies another 14 locations with more than 11 cyclists and model P2 another 12 locations, of which 7 are in agreement. For the remainder, all five of the locations that $\mathrm{P} 2$ predicted as having 11 or more cyclists (in the 3-hour peak period) had 10 or more cyclists in the NB model, and model P2 shows counts similarly close to the 10-cyclist threshold, though to a lesser degree. Moreover, estimated counts at just 18 of the 106 intersections differed by more than 3 cyclists, with an average discrepancy of 5.1 cyclists among these intersections, and those discrepancies attributable to bike trail access, bike lane presence, and/or large curb lane widths (i.e., greater than 4 meters). All this agreement is to be expected: both models relied on the same data set and have just three dissimilar parameters (AADTs in P2, and curb and bike lane widths in NB).

Additional insights can be gleamed by comparing intersection cyclist count model results to the HCM BLOS values for segments leading into those intersections. HCM BLOS values for the modeled segments varied from 3.2 to 6.6 cyclists (for a 3-hour weekday, afternoon period), averaging 5.1, with a standard deviation of 0.54. HCM BLOS values ultimately appeared to offer minimal impact on intersection count predictions, with other factors having greater influence on count model forecasts. Many intersections with intersecting streets having low HCM BLOS values had high counts, and many intersections that had favorable HCM BLOS had low counts. Overall, there appeared to be little correlation, likely due to the previously noted parabolic speed impacts, and the negative sign on the residential indicator coefficient. Nevertheless, merging these datasets does present valuable opportunities: areas with low HCM BLOS and high predicted cyclist counts may be strong candidates for further cycling infrastructure enhancements.

\section{CONCLUSIONS}

This investigation developed a series of direct demand cyclist count models to estimate the number of cyclists on roadway segments in the Seattle Metropolitan area. The models were compared to the HCM's BLOS index, which estimates cyclist suitability and comfort based on roadway characteristics. Consistencies between the count models and the HCM BLOS index show that wider bike lanes and curb lanes, along with lower traffic volumes, create favorable conditions for higher numbers of cyclists. While the two preferred models developed here indicate either the use of curb lane width or bike lane width or automotive traffic volume be used, it is likely that all three variables would become statistically significant if more data points were available. 
The model estimates primarily diverge from HCM BLOS in cases where a roadway feature has positive impacts for cyclist comfort, but suggests little destination attractiveness (such as residential neighborhoods and location with driving speed limits $30 \mathrm{mph}$ and lower). These new models also feature trip generation and attraction terms that provide a more complete and accurate characterization of locations with numerous cyclists. When the cyclist count models and HCM BLOS indices were both applied to Shoreline's roadway network, the two most preferred cyclist count models showed very close predictions to one another, though little correlation with HCM BLOS values for intersecting streets, which is largely due to the residential covariate's effects, and the concavity of speed-limit impacts, on estimated cyclist counts.

In summary, the cyclist count models developed in here show significant promise for forecasting bicycle demand in the Seattle metro area and beyond. While this exploration showed that the count models are still imperfect, it possesses significant utility and may be used by transportation planners to inform decision making, promote cycling, improve safety, and accommodate cyclists within their neighborhoods and regions. Moreover, by combining estimated cyclist counts with the actual levels of service that they are experiencing, locations with the greatest need and/or potential for cycling enhancement may be quickly identified. After all, most cities do not conduct comprehensive bicycle count programs and so lack reliable information as to where cyclists really are. While this model falls short of a comprehensive count program, it gives analysts the tools to generate cyclist count predictions based on readily available roadway characteristics and population and employment information, thus enabling more informed planning and decision making.

\section{REFERENCES}

Allen-Munley, Cheryl, Janice Daniel and Sunil Dhar (2004) Logistic Model for Rating Urban Bicycle Route Safety. Transportation Research Record, 1878, 107-115. Retrieved from http://trb.metapress.com/content/k0650j1531803328/

Bureau of Transportation Statistics (2004) Transportation Statistics Annual Report - September 2004. Washington, D.C.

City of Auburn (2009) Average Daily Traffic Counts. Retrieved from http://www.auburnwa.gov/Assets/PW/AuburnWA/Docs/2009+ADT+Counts.pdf

City of Bothell (2010) Traffic Data Information. Retrieved from http://www.ci.bothell.wa.us/Site/Content/Public\%20Works/Transportation\%20Issues/Traffic_Da ta/2009_ADT_PDF/TrafficCounts2009_Web.pdf

City of Bremerton (2011) Traffic Count Data. Retrieved from http://www.ci.bremerton.wa.us/forms/publicworks/engineering/trafficcounts.pdf

City of Federal Way (2011) 2010 Estimated Weekday ADT. Retrieved from http://www.cityoffederalway.com/DocumentView.aspx?DID=1716 
City of Kent (2009) Average Daily Traffic Volume Map. Retrieved from

http://www.ci.kent.wa.us/publicworks/maps.aspx

City of Kirkland (2008) Traffic Count Summary - Average Daily Traffic in both Directions. Retrieved from http://www.kirklandwa.gov/Assets/Public+Works/Public+Works+PDFs/Transportation/Traffic+ Count+Summary+2007.pdf

City of Lakewood (2010) Traffic Counter Locations and Traffic Volumes for 2009/2010. Retrieved from http://www.cityoflakewood.us/documents/economic_development/ESRI_reports//traffic_volume s_by_counter.pdf

City of Lynwood (2005) Traffic Counts. Retrieved from http://www.ci.lynnwood.wa.us/Content/Services.aspx?id=493

City of Puyallup Transportation Division (2008) 2007 Annual Traffic Counts. Retrieved from http://www.cityofpuyallup.org/files/library/cc26039a74a878fd.pdf

City of Redmond (2010) 2009 Traffic Count Map. Retrieved from

http://www.redmond.gov/cms/one.aspx?portalId=169\&pageId=2865

City of Renton (2010) Traffic Flow Map. Retrieved from

http://rentonwa.gov/uploadedFiles/Living/PBPW/TRANSPOR/2010\%20Traffic\%20Flow\%20M ap.pdf

City of Shoreline (2012a) Quick Facts. Retrieved from

http://www.cityofshoreline.com/index.aspx?page $=44$

City of Shoreline (2012b) Traffic Count Program. Retrieved from

http://www.cityofshoreline.com/index.aspx?page=211

City of Tacoma (2012) Average Daily Traffic Counts - 24 Hour Period. Retrieved from http://www.govme.org/govme/AddApps/Inter/TrafficCounts/g_TrafficCounts_B.asp

Davis, Jeffrey (1995) Bicycle Test Route Evaluation for Urban Road Conditions. Transportation Congress: Civil Engineers - Key to the World Infrastructure, 1, 1063-1076.

Devore, Jay L. (2008) Probability and Statistics for Engineering and the Sciences. California Polytechnic State University, San Luis Obispo.

Eco Counter (2012) Bicycle Sensors. Retrieved from http://www.eco-compteur.com/BicyclesSensors.html?wpid=15037 
Federal Highway Administration (1998) The Bicycle Compatibility Index: A Level of Service Concept, Implementation Manual. FHWA-RD-98-095. Retrieved from http://www.hsrc.unc.edu/research/pedbike/98095/index.html

Federal Highway Administration (2012) Highway Performance Monitoring System. Retrieved from http://www.fhwa.dot.gov/policyinformation/hpms.cfm

Griswold, Julia, Aditya Medury and Robert Schneider (2011) Pilot Models for Estimating Bicycle Intersection Volumes. Transportation Research Record, 2247, 1-7.

Guisan, A and Zimmermann, N (2000) Predictive Habitat Distribution Models in Ecology.

Ecological Modeling, 135, 147-186.

Hochmair, H.H., and Fu, J. (2009) Web Based Bicycle Trip Planning for Broward County, Florida. ESRI User Conference, San Diego, CA. Retrieved from

http://flrec.ifas.ufl.edu/hochmair/pubs/hochmair_fu_ESRI2009.pdf

Kitsap County Public Works (2010) Traffic Count Stations. Retrieved from http://www.kitsapgov.com/pw/tcounts.htm.

KTU\&A (2011) City of Chula Vista Bikeway Master Plan, 2011. Retrieved from http://www.chulavistaca.gov/city_Services/Development_Services/engineering/BikewayMasterP $\underline{\text { lan.asp }}$

Kweon, Young-Jun and Kara Kockelman (2002) Driver Injury Severity: An application of Ordered Probit Model. Accident Analysis and Prevention (34-3) 313-321.

McNeil, Nathan (2011) Bikeability and the 20-min Neighborhood. Transportation Research Record, 2247, 53-63.

National Highway Transportation Safety Agency (2010) Traffic Safety Facts 2009. Retrieved from http://www-nrd.nhtsa.dot.gov/Pubs/811402.pdf

Puget Sound Regional Council (2010a) Bicycle Counts. Retrieved from http://psrc.org/data/transportation/bicycle-counts

Puget Sound Regional Council (2010b) GIS Shapefiles. Retrieved from http://psrc.org/data/gis/shapefiles

San Antonio - Bexar County Metropolitan Planning Organization (2009) San Antonio - Bexar County 2009 Bike Map. Retrieved from http://www.sametroplan.org/Bike_Walk/maps/pub_maps.html

Seattle Department of Transportation (2007) Seattle Master Bicycle Plan. Retrieved from http://www.seattle.gov/transportation/tfdmaps.htm 
1 Seattle Department of Transportation (2011) Traffic Flow and Maps - 2010. Retrieved from

2 http://www.seattle.gov/transportation/tfdmaps.htm

3

4 Syracuse Metropolitan Transportation Council (2003) Bicycle and Pedestrian Plan: Bicycle

5 Suitability Map. Syracuse, New York. Retrieved from http://www.smtcmpo.org/bike-

6 ped/activities/bike-map.asp

8 Transportation Research Board (2010) Highway Capacity Manual. Washington D.C.

9

10 United States Census Bureau (2012) 2010 Census Data. Retrieved from

11 http://2010.census.gov/2010census/data/ 